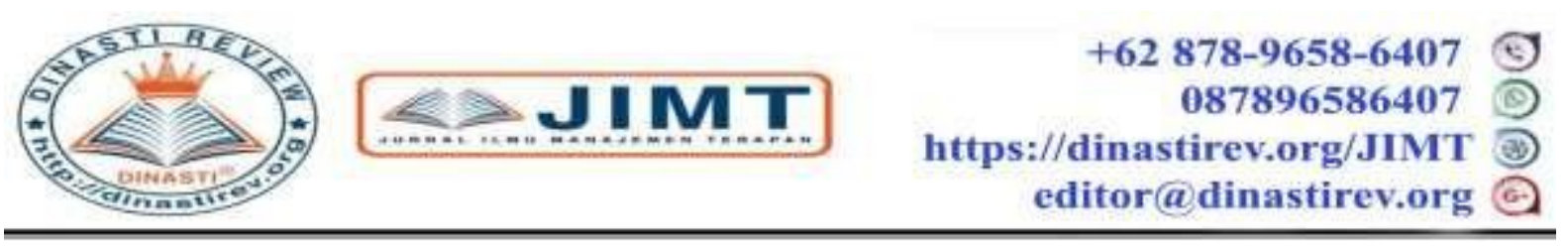

\title{
PENGARUH KESELAMATAN DAN KESEHATAN KERJA (K3), LINGKUNGAN KERJA DAN BEBAN KERJA TERHADAP KINERJA KARYAWA
}

\author{
${ }^{1)}$ Ryani Dhyan Parashakti, ${ }^{2)}$ Putriawati \\ ${ }^{1)}$ Fakultas Ekonomi dan Bisnis Universitas Dian Nusantara, Jakarta, Indonesia \\ ${ }^{2)}$ Fakultas Ekonomi dan Bisnis Universitas Mercu Buana, Jakarta, Indonesia
}

\begin{tabular}{|c|l|}
\hline $\begin{array}{c}\text { ARTICLE INFORMATION } \\
\text { Received: 23/01/2020 } \\
\text { Revised: 10/02/2020 } \\
\text { Issued: 29/02/2020 } \\
\text { (filled in by Editor) }\end{array}$ & $\begin{array}{l}\text { Abstrak: Penelitian ini bertujuan untuk menguji dan } \\
\text { menganalisis pengaruh keselamatan kesehatan kerja } \\
\text { (K3), lingkungan kerja dan beban kerja Terhadap kinerja } \\
\text { karyawan. Objek pada penelitian ini adalah karyawan } \\
\text { PT. Bahagia Idkho Mandiri Bagian Produksi. Sampel } \\
\text { yang digunakan dalam penelitian ini adalah sebanyak 78 } \\
\text { Corresponding Author: } \\
\text { ryaniparasakti@gmail.com } \\
\text { ini adalah Component atau Variance Based Structural } \\
\text { Equation Model. Dengan metode deskriptif kuantitatif. } \\
\text { Analisis data yang di gunakan adalah analisis statistic } \\
\text { dalam bentuk SEM PLS. hasil penelitian ini menunjukan } \\
\text { bahwa keselamatan kesehatan kerja berpengaruh positif } \\
\text { signifikan terhadap kinerja karyawan PT. Bahagia Idkho } \\
\text { Mandiri Bagian Produksi. Lingkungan kerja berpengaruh } \\
\text { positif signifikan terhadap kinerja karyawan PT. Bahagia } \\
\text { Idkho Mandiri Bagian Produksi. Beban kerja } \\
\text { berpengaruh positif signifikan terhadap kinerja karyawan } \\
\text { PT. Bahagia Idkho Mandiri Bagian Produksi. }\end{array}$ \\
& \\
DOI:10.31933/JIMT &
\end{tabular}

\section{PENDAHULUAN}

Sumber daya manusia (SDM) di perusahaan perlu dikelola secara profesional agar terwujud keseimbangan antara kebutuhan pegawai dengan tuntutan dan kemampuan organisasi perusahaan. Keseimbangan tersebut merupakan kunci utama perusahaan agar dapat berkembang secara produktif dan wajar (Mangkunegara, 2009). Berkaitan dengan hal tersebut, karyawan merupakan sumber daya penting yang wajib perusahaan jaga. Oleh karena itu bagi perusahaan yang khususnya bergerak dibidang perdagangan yang mengandalkan tingkat kinerja pegawai diperusahaannya, maka perusahaan tersebut dituntut untuk mampu mengoptimalkan kinerja karyawannya.

Salah satu faktor yang mempengaruhi tingkat keberhasilan suatu organisasi adalah kinerja karyawan. Kinerja karyawan menurut Mangkunegara dalam Carudin (2011) adalah 
hasil kerja secara kualitas dan kuantitas yang dicapai oleh seorang karyawan dalam melaksanakan tugasnya sesuai dengan tanggung jawab yang diberikan kepadanya. Setiap perusahaan selalu mengharapkan mempunya prestasi, karena dengan memiliki karyawan yang berprestasi akan memberikan sumbangan yang optimal bagi perusahaan. Selain itu dengan memiliki karyawan yang berprestasi perusahaan dapat meningkatkan kinerja perusahaannya. Apabila individu dalam perusahaan yaitu sumber daya manusia berjalan efektif, maka perusahaan juga tetap berjalan efektif. Dengan kata lain kelangsungan suatu perusahaan ditentukan oleh kinerja karyawan. Faktor keamanan dan perlindungan dalam bekerja yang menjadi salah satu faktor yang mempengaruhi kinerja karyawan. Ketika karyawan memiliki rasa aman dan nyaman karena dirinya merasa mendapatkan perlindungan yang baik dari perusahaan, maka karyawan tersebut juga akan bekerja dengan perasaan yang tenang dan akan bekerja secara baik.

Menurut Mangkunegara (2009) keselamatan kerja adalah perlindungan karyawan dari luka-luka yang disebabkan oleh kecelakaan yang terkait dengan pekerjaan. Resiko keselamatan mencakup aspek-aspek dari lingkungan kerja yang dapat menyebabkan kebakaran, ketakutan aliran listrik terpotong, luka memar, keseleo, patah tulang, kerugian alat tubuh, pengelihatan, pendengaran. Kesehatan kerja merupakan usaha dan aturan-aturan untuk menjaga kondisi perubahan dari kejadian atau keadaan yang merugikan kesehatan dan kesusilaan, baik keadaan yang sempurna fisik, mental maupun sosial sehingga memungkinkan seseorang dapat bekerja dengan optimal. Menurut Suma'mur (2009), kesehatan kerja adalah ilmu kesehatan dan penerapannya yang bertujuan mewujudkan tenaga kerja sehat, produktif dalam bekerja, berada dalam keseimbangan yang mantap antara kapasitas kerja, beban kerja dan keadaan lingkungan kerja, serta terlindung dari penyakit yang disebabkan oleh pekerjaan dan lingkungan kerja. kesehatan kerja memiliki sifat medis dan sasarannya adalah tenaga kerja (pekerja) Selain faktor motivasi kerja lingkungan kerja tempat karyawan tersebut bekerja juga tidak kalah pentingnya dalam meningkatkan kinerja karyawan. Lingkungan kerja yang sesuai dapat mendukung pelaksanaan kerja sehingga karyawan memiliki semangat bekerja dan meningkatkan kinerja karyawan, sedangkan ketidak sesuaian lingkungan kerja dapat menciptakan ketidaknyamanan bagi karyawan dalam melaksanakan tugas-tugasnya.

Menurut Darvis (dalam Ekaningsih, 2012) Lingkungan kerja dalam suatu organisasi mempunyai arti penting bagi individu yang bekerja di dalamnya, karena lingkungan ini akan mempengaruhi secara langsung maupun tidak langsung manusia yang ada di dalamnya. Hal ini ada tiga alasan, ada bukti yang menunjukan bahwa tugas dapat diselesaikan dengan lebih baik pada lingkungan kerja organisasi yang baik, ada bukti bahwa manager dapat mempengaruhi lingkungan kerja dalam organisasi atau unit kerja yang dipimpin, kecocokan antara individu dengan organisasi mempunyai peranan yang sangat penting dalam mencapai prestasi dan kepuasan individu itu sendiri dalam organisasi. Sedarmayanti (2009), mengemukakan secara garis besar jenis lingkungan kerja terbagi menjadi dua bagian yaitu, lingkungan kerja fisik semua keadaan yang berbentuk fisik yang terdapat di sekitar tepat kerja yang dapat mempengaruhi pegawai baik secara langsung maupun tidak langsung. Sedangkan lingkungan kerja non fisik adalah semua keadaan yang terjadi berkaitan dengan hubungan kerja dengan atasan maupun hubungan dengan rekan kerja. Untuk mengelola hubungan kerja yang baik dengan orang lain maka diperlukan, pengaturan waktu, tahu posisi diri, memahami dampak kata-kata atau tindakan anda pada diri orang lain.

Selain keselamatan dan kesehatan kerja, lingkungan kerja, faktor lain yang mempengaruhi kinerja karyawan adalah beban kerja. Beban kerja seseorang sudah ditentukan 
dalam bentuk standar kerja perusahaan menurut jenis pekerjaannya. Menurut Astianto dan Suprihhadi (2014), Beban kerja karyawan dapat terjadi dalam tiga kondisi. Pertama, beban kerja sesuai standar. Kedua, beban kerja yang terlalu tinggi (over capacity). Ketiga, beban kerja yang terlalu rendah (under capacity). Beban-beban terlalu berat atau terlalu tinggi akan berpengaruh terhadap kinerja karyawan sehingga mengakibatkan turunnya kinerja karyawan.

PT. Bahagia Idkho Mandiri adalah perusahaan yang bergerak dibidang industry kosmetik dengan merk dagang MBK. Logo MBK berupa kembang sepatu berwarna merah. PT. Bahagia Idkho Mandiri didirikan pada tanggal 29 Januari 2006. PT. Bahagia Idkho Mandiri berlokasi di Kawasan Industri Mekar Jaya J1. Raya Mauk KM 7 Karet III No. 1 Sepatan - Tangerang. Masalah yang terjadi di PT. Bahagia Idkho Mandiri adalah belum tercapainya target penjualan yang telah ditetapkan perusahaan karena terlalu tingginya standar target penjualan.

Pada umumnya karyawan juga dituntut untuk bekerja dalam waktu kerja yang sangat singkat dan tidak sesuai dengan pekerjaan yang diberikan oleh atasannya. Dan perusahaan pun harus lebih memperhatikan penurunan kinerja karyawan ini dan harus segera membenahinya. Karena akan berdampak buruk bagi perusahaan jika tidak segera dibenahi. Hal ini menunjukan bahwa masih banyak yang harus diperbaiki agar produksi dapat mencapai target yang sudah ditentukan perusahaan.

Keselamatan dan kesehatan kerja (K3) merupakan salah satu hak asasi dan salah satu upaya untuk meningkatkan kualitas kerja karyawan diperusahaan itu sendiri. Menurut Ardana, dkk (2012) keselamatan dan kesehatan kerja (K3) adalah upaya perlindungan yang ditujukan agar tenaga kerja dan orang lain ditempat kerja atau selalu dalam keadaan selamat dan sehat sehingga setiap sumber produksi dapat digunakan secara aman dan efisien.

Suatu kondisi lingkungan kerja dikatakan baik atau sesuai apabila manusia dapat melaksanakan kegiatan secara optimal, sehat, aman dan nyaman. Kesesuaian lingkungan kerja dapat dilihat akibatnya dalam jangka waktu yang lama. Menurut Sunyoto (2012), lingkungan kerja merupakan bagian komponen yang sangat penting didalam karyawan melakukan aktivitas kerja. Dengan memperhatikan lingkungan kerja yang baik atau menciptakan kondisi kerja yang mampu memberikan motivasi untuk bekerja, maka akan membawa pengaruh terhadap kegairahan atau semangat karyawan bekerja.

Sesuai dengan uraian pada latar belakang dan rumusan masalah diatas, maka tujuan yang ingin penulis capai dari penelitian ini: (1) Untuk mengetahui Pengaruh Kesehatan dan Keselamatan Kerja berpengaruh terhadap Kinerja Karyawan PT. Bahagia Idkho Mandiri; (2) Untuk mengetahui Lingkungan Kerja berpengaruh terhadap Kinerja Karyawan PT. Bahagia Idkho Mandiri; (3) Untuk mengetahui Beban Kerja berpengaruh terhadap Kinerja Karyawan PT. Bahagia Idkho Mandiri.

\section{KAJIAN PUSTAKA}

\section{Keselamatan dan Kesehatan Kerja (K3)}

Keselamatan dan kesehatan kerja (K3) adalah kondisi yang harus diwujudkan di tempat kerja dengan segala daya upaya berdasarkan ilmu pengetahuan dan pemikiran mendalam guna melindungi tenaga kerja, manusia serta karya dan budayanya melalui penerapan teknologi pencegahan kecelakaan yang dilaksanakan secara konsisten sesuai dengan peraturan perundangan dan standar yang berlaku (Ryani, dkk 2019). 


\section{Lingkungan Kerja}

Lingkungan kerja dalam suatu perusahaan sangat penting untuk diperhatikan manajemen. Meskipun lingkungan kerja tidak melaksanakan proses produksi suatu perusahaan, namun lingkungan kerja mempunyai pengaruh langsung terhadap para karyawan. Lingkungan kerja adalah suasana dimana karyawan bekerja dan melakukan aktivitas setiap harinya.

\section{Beban Kerja}

Beban kerja menurut Meshkati dalam Hariyati (2011) dapat di definisikan sebagai suatu perbedaan antara kapasitas atau kemampuan pekerja dengan tuntutan pekerjaan yang harus dihadapi. Mengingat kerja manusia bersifat mental dan fisik, maka masing-masing mempunyai tingkat pembebanan yang berbeda-beda.

\section{Kinerja Karyawan}

Kinerja juga dapat diartikan sebagai hasil kerja yang dicapai seseorang dalam melaksanakan tugas-tugas yang dibebankan kepadanya yang didasarkan atas kecakapan, pengalaman, kesungguhan, serta waktu (Hasibuan, 2009). Jadi dapat disimpulkan bahwa kinerja merupakan hasil kerja yang dicapai seseorang dalam melaksanakan tugas yang diberikan kepadanya sesuai dengan kriteria yang ditetapkan. Kinerja dapat digunakan sebagai ukuran hasil kerja secara kualitas dan kuantitas yang telah dicapai oleh seorang karyawan atau pegawai dalam melaksanakan tugas sesuai dengan tanggung jawab yang telah dibebankan kepadanya.

\section{Pengembangan Hipotesis dan Rerangka Berpikir}

H1 : Pengaruh Keselamatan dan Kesehatan Kerja (K3) Terhadap Kinerja Karyawan H2 : Pengaruh Lingkungan Kerja Terhadap Kinerja Karyawan

H3 : Pengaruh Beban Kerja Terhadap Kinerja Karyawan

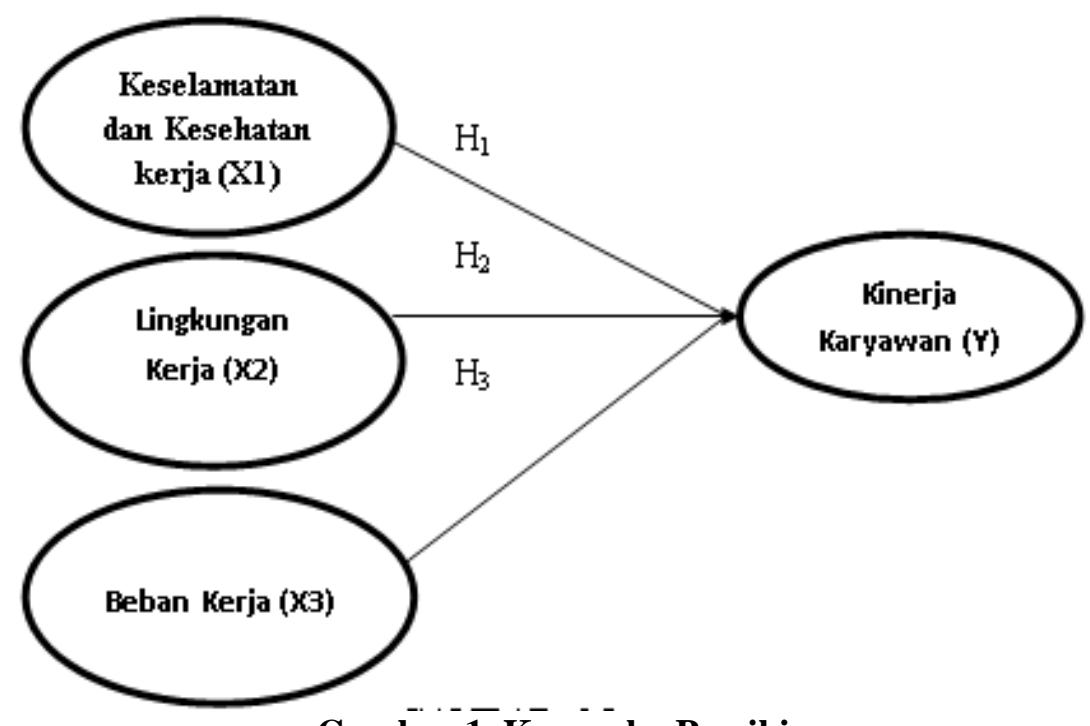

Gambar 1. Kerangka Pemikiran

\section{METODE PENELITIAN}

Proses penelitian ini diawali dengan kegiatan mengidentifikasi permasalahan dimana waktu dan tempat penelitian ini dimulai sejak April 2018. Peneliti memilih objek penelitian pada PT. Bahagia Idkho Mandiri, yang berlokasi di Kawasan Industri Mekar Jaya Jl. Raya Mauk KM 7 Karet III No. 1 Sepatan - Tangerang. 


\section{Populasi dan Sampel Penelitian}

Populasi dalam penelitian ini adalah seluruh karyawan dibagian produksi pada PT. Bahagia Idkho Mandiri yang memiliki jumlah karyawaan 350 orang.

Sampel adalah bagian dari populasi yang dipergunakan sebagai sumber data yang sebenarnya. Dengan kata lain sampel merupakan bagian dari populasi. Dari keseluruhan karyawan yang menjadi populasi tersebut, Penentuan sampel yang digunakan dalam penelitian ini sampel dipilih secara non probability sampling. Non probability sampling yaitu teknik pengambilan sampel yang tidak memberi peluang yang sama bagi setiap unsur atau anggota populasi untuk dipilih menadi sampel (Sugiyono ,2011). Rumus pengambilan sampel dengan menggunakan rumus Slovin dengan jumlah sampel sebanyak 78 responden.

\section{Analisi Korelasi}

\section{Analisis Deskriptif (Descriptive Analysis)}

Menurut Sugiyono (2013) analisis deskriptif adalah statistik yang digunakan untuk menganalisis data dengan cara mendeskripsikan atau menggambarkan data yang telah terkumpul sebagaimana adanya tanpa bermaksud membuat kesimpulan yang berlaku untuk umum atau generalisasi. Metode analisis data dalam penelitian ini merupakan Comporement atau Variance Basical Structural Equation Modeling dimana dalam pengolahan data menggunakan program PLS (Partial Least Square) Versi 3.0.

SEM (Structural Equation Modeling) - PLS (Partial Least Square) Structural Equation Modeling (SEM) merupakan teknik analisis yang memungkinkan pengujian sebuah rangkaian hubungan secara simultan (Noor, 2011). Hubungan ini dibangun antara satu atau beberapa variabel independen dengan satu atau beberapa variabel dependen. Metode analisis data dalam penelitian ini menggunakan component atau variance based Structural Equation Modeling (SEM) dimana dalam pengolahan datanya menggunakan program Smart-Partial Least Square (Smart-PLS) versi 3.0. PLS (Partial Least Square) adalah model dari variance based SEM. PLS dimaksudkan untuk causal perdictive analysis dalam situasi kompleksitas yang tinggi dan dukungan teori yang rendah (Ghozali, 2014).

\section{Evaluasi Measurement (outer) Model Convergent Validity}

Pengujian convergent validity dari masing-masing indicator konstruk. Menurut Chin dalam Ghozali (2014), suatu indicator dikatakan mempunyai realibilitas yang baik jika nilainya lebih besar dari 0,70, sedangkan loading factor 0,50 sampai 0,60 dapat dianggap cukup. Berdasarkan kriteria inibila ada loading factor dibawah 0,50 maka akan didrop dari model (Ghozali, 2014).

\section{Discriminant Validity}

Pengujian discriminant validity, indikator reflektif dapat dilihat pada crossloading antara indikator dengan konstruknya. Suatu indikator dinyatakan valid jika mempunyai loading factor tertinggi kepada konstruk yang dituju dibandingkan loading factor kepada konstruk lain. Dengan demikian, kontrak laten memprediksi indikator pada blok mereka lebih baik dibandingkan dengan indikator di blok yang lain (Ghozali, 2014).

\section{Average Variance Extracted (AVE)}

Model mempunyai discriminant validity yang cukup jika akar AVE untuk setiap konstruk lebih besar daripada korelasi antara konstruk dan konstruk lainnya. Menilai validitas dari suatu konstruk dengan dengan melihat nilai AVE, dipersyaratkan model yang baik kalau AVE masingmasing konstruk nilainya lebih besar dari 0,05 (Ghozali, 2014).

\section{Composite Reliability dan Cronbach Alpha}

Pengujian composite reliability dan cronbach alpha bertujuan untuk menguji validitas 
instrumen dalam suatu model penelitian. Atau mengukur internal consistency dan nilainya harus di atas 0,60 . Apabila seluruh nilai variabel lain memiliki nilai composite reliability maupun cronbach alpha $\geq 0,7$ hal itu berarti bahwa konstruk memiliki reabilitas yang baik atau kuisioner yang digunakan sebagai alat dalam penelitian ini sudah konsisten (Ghozali, 2014).

\section{Pengujian Model Struktural Atau Uji Hipotesis (Inner Model)}

Pengujian inner model adalah pengembangan model berbasis konsep dan teori dalam rangka menganalisis hubungan antara variabel eksogen dan endogen telah dijabarkan dalam kerangka konseptual.Tahap pengujian terhadap model struktural (uji hipotesis) dilakukan dengan langkah-langkah sebagai berikut:
a. Nilai R-Square
b. Goodness of Fit Model
c. Hasil Pengujian Hipotesis (Estimasi Koefisien Jalur)

\section{HASIL DAN PEMBAHASAN}

\section{Pengujian Instrumen}

\section{Convergent Validity}

Pengujian Convergent Validity dari masing-masing model indikator konstruk. Menurut Chin dalam Ghozali (2014), suatu indikator dikatakan mempunyai valid yang baik jika nilainya lebih besar dari 0,70, sedangkan loading factor 0,50-0,60 dapat dianggap cukup. Berdasarkan kriteria ini bila ada loading factor dibawah 0,50 maka akan di drop dari model.

Tabel 1. Hasil Pengujian Convergent Validity

\begin{tabular}{|c|c|c|c|}
\hline VARIABEL & INDIKATOR & OUTER LOADINGS & KETERANGAN \\
\hline \multirow{10}{*}{$\begin{array}{c}\text { KESELAMATAN } \\
\text { KESEHATAN } \\
\text { KERJA }\end{array}$} & K31 & 0,857 & VALID \\
\hline & K310 & 0,919 & VALID \\
\hline & K32 & 0,912 & VALID \\
\hline & K33 & 0,935 & VALID \\
\hline & K34 & 0,699 & VALID \\
\hline & K35 & 0,840 & VALID \\
\hline & K36 & 0,849 & VALID \\
\hline & K37 & 0,777 & VALID \\
\hline & K38 & 0,830 & VALID \\
\hline & K39 & 0,883 & VALID \\
\hline \multirow{9}{*}{$\begin{array}{c}\text { LINGKUNGAN } \\
\text { KERJA }\end{array}$} & LK1 & 0,731 & VALID \\
\hline & LK2 & 0,860 & VALID \\
\hline & LK3 & 0,853 & VALID \\
\hline & LK4 & 0,833 & VALID \\
\hline & LK5 & 0,869 & VALID \\
\hline & LK6 & 0,610 & VALID \\
\hline & LK7 & 0,567 & VALID \\
\hline & LK8 & 0,417 & TIDAK VALID \\
\hline & LK9 & 0,624 & VALID \\
\hline \multirow{7}{*}{ BEBAN KERJA } & BK1 & 0,696 & VALID \\
\hline & BK2 & 0,710 & VALID \\
\hline & BK3 & 0,851 & VALID \\
\hline & BK4 & 0,846 & VALID \\
\hline & BK5 & 0,709 & VALID \\
\hline & BK6 & 0,683 & VALID \\
\hline & BK7 & 0,483 & TIDAK VALID \\
\hline \multirow[b]{3}{*}{ KINERJA } & KK1 & 0,490 & TIDAK VALID \\
\hline & KK10 & 0,737 & VALID \\
\hline & KK2 & 0,832 & VALID \\
\hline
\end{tabular}




\begin{tabular}{cccc}
\hline KARYAWAN & KK3 & 0,852 & VALID \\
\cline { 2 - 4 } & KK4 & 0,635 & VALID \\
\cline { 2 - 4 } & KK5 & 0,692 & VALID \\
\cline { 2 - 4 } & KK6 & 0,530 & VALID \\
\cline { 2 - 4 } & KK7 & 0,433 & TIDAK VALID \\
\cline { 2 - 4 } & KK8 & 0,672 & VALID \\
\hline
\end{tabular}

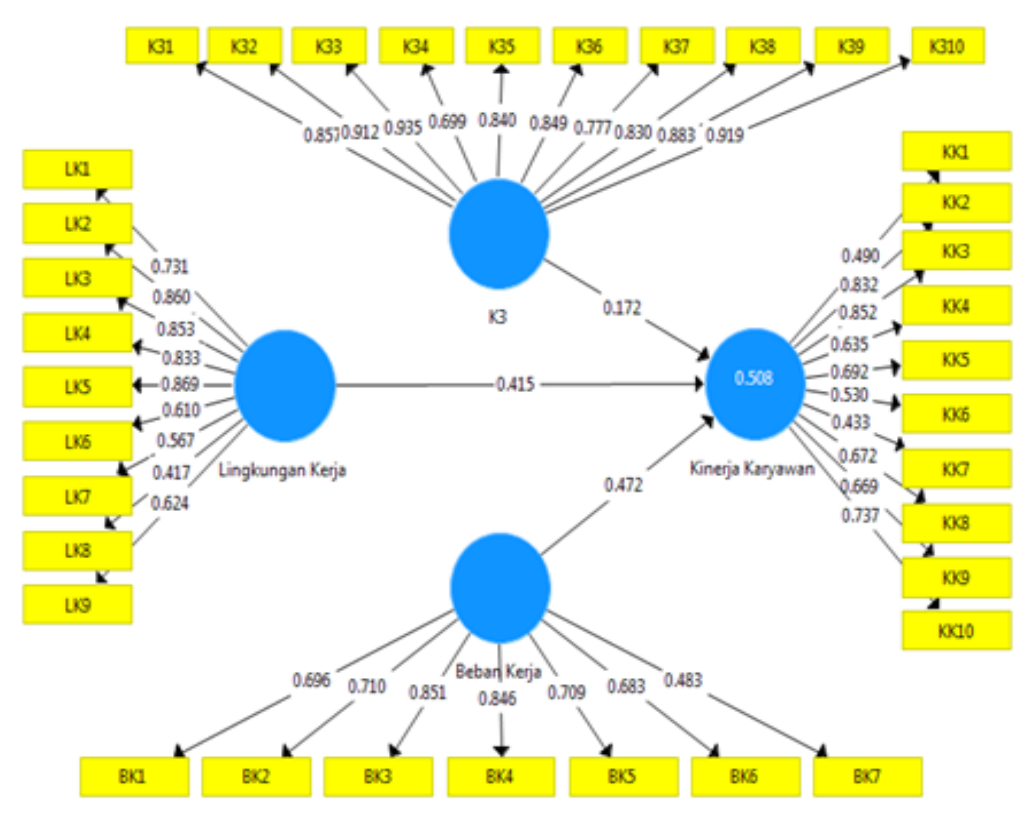

Gambar 2. Hasil Alogaritma PLS

Berdasarkan pada Tabel 1 dan Gambar 2 dapat diketahui bahwa indicator LK8, BK7, KK1 dan KK7 memiliki nilai loading factor kurang dari 0.50 yang dinyatakan tidak valid dan tidak signifikan. Oleh karena itu, indikator tersebut akan dihilangkan dari model. Berikut hasil dari penghilangan indikator dan penghitungan kembali: 


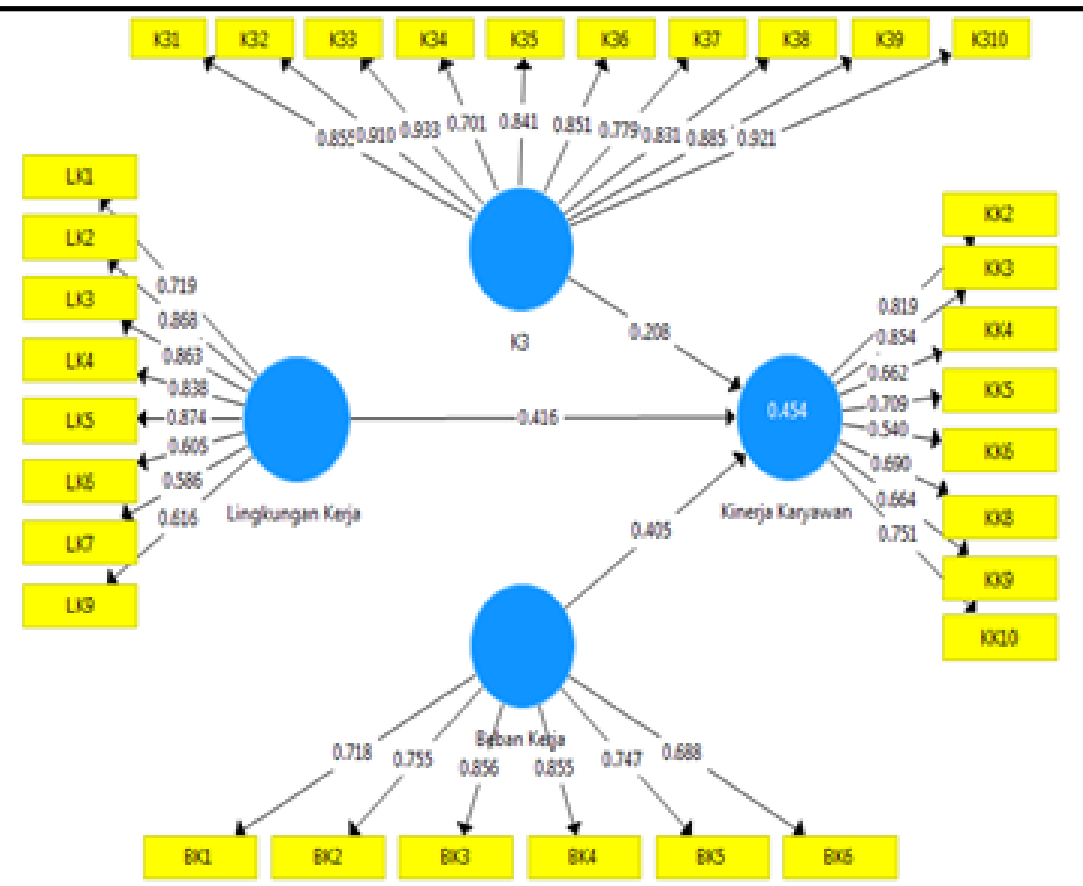

Gambar 3. Hasil Boostrapping

Sumber: Output PLS

Tabel 2. Hasil Pengujian Convergent Validity (Modifikasi)

\begin{tabular}{|c|c|c|c|}
\hline VARIABEL & INDIKATOR & $\begin{array}{c}\text { OUTER } \\
\text { LOADINGS }\end{array}$ & $\begin{array}{c}\text { KETERANG } \\
\text { AN }\end{array}$ \\
\hline \multirow{10}{*}{$\begin{array}{c}\text { KESELAMATAN } \\
\text { KESEHATAN KERJA } \\
(\text { K3) }\end{array}$} & K31 & 0,855 & VALID \\
\hline & K310 & 0,921 & VALID \\
\hline & K32 & 0,910 & VALID \\
\hline & K33 & 0,933 & VALID \\
\hline & K34 & 0,701 & VALID \\
\hline & K35 & 0,841 & VALID \\
\hline & K36 & 0,851 & VALID \\
\hline & K37 & 0,779 & VALID \\
\hline & K38 & 0,831 & VALID \\
\hline & K39 & 0,885 & VALID \\
\hline \multirow{8}{*}{$\begin{array}{c}\text { LINGKUNGAN } \\
\text { KERJA }\end{array}$} & LK1 & 0,719 & VALID \\
\hline & LK2 & 0,868 & VALID \\
\hline & LK3 & 0,863 & VALID \\
\hline & LK4 & 0,838 & VALID \\
\hline & LK5 & 0,874 & VALID \\
\hline & LK6 & 0,605 & VALID \\
\hline & LK7 & 0,586 & VALID \\
\hline & LK9 & 0,616 & VALID \\
\hline \multirow{6}{*}{ BEBAN KERJA } & BK1 & 0,718 & VALID \\
\hline & BK2 & 0,755 & VALID \\
\hline & BK3 & 0,856 & VALID \\
\hline & BK4 & 0,855 & VALID \\
\hline & BK5 & 0,747 & VALID \\
\hline & BK6 & 0,688 & VALID \\
\hline \multirow{7}{*}{$\begin{array}{c}\text { KINERJA } \\
\text { KARYAWAN }\end{array}$} & KK10 & 0,751 & VALID \\
\hline & KK2 & 0,819 & VALID \\
\hline & KK3 & 0,854 & VALID \\
\hline & KK4 & 0,662 & VALID \\
\hline & KK5 & 0,709 & VALID \\
\hline & KK6 & 0,540 & VALID \\
\hline & KK8 & 0,690 & VALID \\
\hline
\end{tabular}


Sumber: Output PLS

KK9 $0,664 \quad$ VALID

Tabel 3. Composite Reliability

\begin{tabular}{|c|c|c|}
\hline Variabel & Composite Reliability & Cronbach's Alpha \\
\hline Beban Kerja & 0,898 & 0,868 \\
\hline K3 & 0,964 & 0,960 \\
\hline Kinerja Karyawan & 0,893 & 0,863 \\
\hline Lingkungan Kerja & 0,912 & 0,887 \\
\hline
\end{tabular}

Hasil dari modifikasi pengujian convergent validity diatas, dapat dilihat bahwa semua indikator telah memenuhi convergent validity karena memiliki nilai Loading factor diatas 0.50 sehingga dapat dikatakan indikator tersebut sudah valid (signifikan).

\section{Discriminant Validity}

Pengujian discriminant validity dilakukan untuk memastikan bahwa setiap konsep dari masing-masing variabel independen berbeda dengan variabel lainnya. Konstruk yang mempunyai discriminant validity yang baik jika setiap nilai loading factor dari setiap indikator dari sebuah variabel independen memiliki nilai loading factor yang paling besar dengan nilai loading factor lain terhadap variabel laten lainnya. Hasil pengujian discrimninant validity diperoleh sebagai berikut:

Tabel 4. Uji Discriminant Validity (Fornell Larcker)

\begin{tabular}{lrrrr}
\hline & Beban Kerja & Kinerja Karyawan & K3 & Lingkungan Kerja \\
\hline Beban Kerja & 0,772 & & & \\
\hline K3 & 0,122 & 0,853 & & \\
\hline $\begin{array}{l}\text { Kinerja } \\
\text { Karyawan }\end{array}$ & 0,485 & 0,277 & 0,717 & \\
\hline $\begin{array}{l}\text { Lingkungan } \\
\text { Kerja }\end{array}$ & 0,132 & 0,048 & 0,480 & 0,756 \\
\hline
\end{tabular}

Sumber: Output PLS

Berdasarkan Tabel 4 dapat dilihat bahwa beberapa nilai loading factor untuk setiap indikator dari masing-masing variabel laten sudah memiliki nilai loading factor yang paling besar dibanding nilai loading jika dihubungkan dengan variabel laten lainnya. Hal ini berarti bahwa setiap variabel laten memiliki discriminant validity yang baik dimana beberapa variabel laten masih memiliki pengukur yang berkorelasi tinggi dengan konstruk lainnya.

Tabel 5. Hasil Pengujian Average Variance Extracted (AVE)

\begin{tabular}{l|l}
\hline Variabel & Average Variance Extracted (AVE) \\
\hline Beban Kerja & 0,597 \\
K3 & 0,728 \\
Kinerja Karyawan & 0,514 \\
Lingkungan Kerja & 0,571 \\
\hline
\end{tabular}

Sumber: Output PLS

Berdasarkan Tabel 5, dapat disimpulkan bahwa akar kuadrat dari Average Variance Extracted (AVE) untuk setiap konstruk lebih besar daripada korelasi antara konstruk yang satu 
dengan konstruk yang lainnya dalam model. Dari nilai AVE tersebut, maka konstruk dalam model yang diestimasi memenuhi kriteria discriminant validity.

\section{Composite Reliability dan Cronbachs Alpha}

Pengujian composite reliability dan cronbach alpha bertujuan untuk menguji reliabilitas instrumen dalam suatu model penelitian, apabila seluruh nilai variabel independen memiliki nilai composite reliability maupun cronbach alpha $\geq 0,7$ hal itu menunjukan bahwa konstruk memiliki reliabilitas yang baik atau kuisioner yang digunakan sebagai alat dalam penelitian ini sudah konsisten. Berikut adalah nilai composite reliability dan cronbach alpha pada output:

Composite reliability adalah kelompok indikator yang mengukur sebuah variabel yang memiliki reliabilitas komposit yang baik jika memiliki composite reliability > 0.7. Dan dapat disimpulkan bahwa, kuesioner yang digunakan sebagai alat penelitian ini telah andal atau konsisten.

\section{Pengujian Model Struktural/Uji Hipotesis (Inner Model)}

Pengujian inner model adalah pengembangan model berbasis konsep dan teori dalam rangka menganalisis hubungan antara variabel eksogen dan endogen yang telah dijabarkan dalam rerangka konseptual. Tahapan pengujian terhadap model structural (uji hipotesis) dilakukan dengan langkah-langkah berikut:

\section{Nilai $R$-Square}

Pengujian terhadap model struktural dilakukan dengan melihat nilai $R$-square yang merupakan uji goodness-fit model. Hasil $R$-square untuk variabel laten endogen dapat dilihat pada tabel berikut ini:

Tabel 6. Nilai $R^{2}$ Variabel Endogen

\begin{tabular}{l|l|}
\hline & R-Square \\
\hline Kinerja Karyawan & 0,454 \\
\hline
\end{tabular}

Sumber: Output PLS

Dari data diatas dapat disimpulkan bahwa nilai R-Square sebesar 0,454 yang berarti variabilitas Kinerja Karyawan ( KK ) yang dapat dijelaskan oleh ketiga variabel dalam model yaitu Keselamatan Kesehatan Kerja, Lingkungan Kerja dan Beban Kerja sebesar 45,4\% sedangkan 54,5\% dijelaskan oleh variabel lain yang tidak diteliti dalam model ini.

\section{Goodness of Fit Model}

Pengujian Goodness of Fit model struktural pada inner model menggunakan nilai predictive relevance $\left(Q^{2}\right)$. Nilai $\quad$ Q-square lebih besar dari 0 (nol) menunjukkan bahwa model mempunyai nilai predictive relevance. Nilai R-square tiap-tiap variabel endogen dalam penelitian ini dapat dilihat pada perhitungan berikut ini:

Nilai predictive relevance diperoleh dengan rumus:

$$
\begin{aligned}
& \mathrm{Q}^{2}=1-(1-\mathrm{R} 1) \\
& \mathrm{Q}^{2}=1-(1-0.150) \\
& \mathrm{Q}^{2}=1-(0.850) \\
& \mathrm{Q}^{2}=0.150 \\
& \mathrm{Q}^{2}=1-(1-\mathrm{R} 2) \\
& \mathrm{Q}^{2}=1-(1-0.331) \\
& \mathrm{Q}^{2}=1-(0.669)
\end{aligned}
$$




$$
\mathrm{Q}^{2}=0.331
$$

Hasil perhitungan diatas memperlihatkan nilai predictive relevance sebesar $0.150>0$ dan $0.331>0$. Hal itu berarti bahwa 15,0\% variasi pada variabel Turnover Intention dan untuk nilai $36.9 \%$ variasi pada variabel Organizational Citizenship Behavior (dependen variabel) dijelaskan oleh variabel-variabel yang digunakan, dengan demikian model dikatakan layak untuk memiliki nilai prediktif yang relevan.

\section{Hasil Pengujian Hipotesis (Estimasi Koefisien Jalur)}

Nilai estimasi untuk hubungan jalur dalam model struktural harus signifikan. Nilai signifikan ini dapat diperoleh dengan prosedur boostrapping. Melihat signifikansi pada hipotesis dengan melihat nilai koefisien parameter dan nilai signifikansi $\mathrm{t}$ statistik pada algorithm boostrapping report. Untuk mengetahui signifikan atau tidak signifikan dilihat dari t-table pada alpha 0,05 (5\%) 1.96. Kemudian t-table dibandingkan dengan t-hitung (t- statistik).

Tabel 7. Hasil Pengujian Hipotesis

\begin{tabular}{|c|c|c|c|c|c|}
\hline & $\begin{array}{l}\text { 0riginal } \\
\text { Sample (0) }\end{array}$ & $\begin{array}{c}\text { Sample } \\
\text { Mean } \\
\text { (Mi) }\end{array}$ & $\begin{array}{l}\text { Standari } \\
\text { Deniation } \\
\text { (STDEW) }\end{array}$ & $\begin{array}{c}\text { TStatistics } \\
(\mid 0 \text { STDERV })\end{array}$ & $\begin{array}{c}\mathrm{P} \\
\text { Talues }\end{array}$ \\
\hline $\begin{array}{l}\text { Beban Kerja-s } \\
\text { Kinerja Karyawan }\end{array}$ & $0,40 j$ & {$[, 4,0]$} & $0,1,09$ & 4,111 & 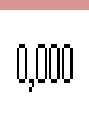 \\
\hline $\begin{array}{l}\text { K } \& \text { Kinerja } \\
\text { Karywan }\end{array}$ & 0,010 & $0,0] ?$ & 0,066 & 2,410 & {$[1,[1] 6$} \\
\hline $\begin{array}{l}\text { Linghugan Kerjas } \\
\text { Kinerjaryara }\end{array}$ & 0,416 & {$[, 431$} & [1,110] & 3,60 & [إ]|[ון, \\
\hline
\end{tabular}

Sumber: PLS

Dari Tabel 7 di atas, dijelaskan beberapa hal sebagai berikut:

\section{Pengaruh Keselamatan Kesehatan Kerja Terhadap Kinerja Karyawan}

Berdasarkan hasil tabel 4.14 dapat disimpulkan bahwa variabel keselamatan kesehatan kerja ber pengaruh positif signifikan terhadap kinerja karyawan. Hal ini ditunjukan dengan nilai original sample sebesar 0,208 dan nilai t-statistik sebesar 2,410 lebih besar dari t-tabel sebesar 1,96 dan hipotesis yang diterima, yang menyatakan bahwa apabila dapat disimpulkan bahwa keselamatan kesehatan kerja (K3) secara persial berpengaruh positif dan signifikan terhadap kinerja karyawan. Artinya, keselamatan dan kesehatan kerja (K3) yang baik akan menunjukan adanya pengaruh terhadap kinerja karyawan PT. Bahagia Idkho Mandiri.

Pada kenyataannya program K3 yang diberikan perusahaan terhadap karyawan PT. Bahagia Idkho Mandiri sangat membantu untuk meningkatkan kinerja karyawan karena dengan hampir seluruh kegiatannya yang berada dilapangan dan dapat menimbulkan sebuah resiko musibah ataupun kecelakaan kerja kapan dan dimana saja, program ini dinilai oleh karyawan dapat memberikan rasa aman dalam melaksankan tanggung jawabnya. Sesuai dengan pendapat Mangkunegara (2010) "selain bertujuan menghindari kecelakaan kerja dalam proses produksi perusahaan, program keselamatan juga meningkatkan kegairahan, keserasian kerja, dan partisipasi kerja karyawan" dengan meningkatnya kegairahan, keserasian kerja dan partisipasi kerja maka berdampak pada meningkatnya kinerja karyawan.

\section{Pengaruh Lingkungan Kerja Terhadap Kinerja Karyawan}

Berdasarkan hasil tabel 4.14 dapat disimpulkan bahwa variabel lingkungan kerja 
berpengaruh positif signifikan terhadap kinerja karyawan. Hal ini ditunjukan dengan nilai original sample sebesar 0,416 dan nilai t-statistik sebesar 3,769 lebih besar dari t-tabel sebesar 1,96 dan hipotesis yang diterima, Sehingga dapat disimpulkan bahwa lingkungan kerja secara persial berpengaruh positif signifikan terhadap kinerja karyawan.

Pada kenyataannya, Hasil penelitian yang sudah dilakukan menunjukkan lingkungan kerja karyawan PT. Bahagia Idkho Mandiri termasuk dalam kategori baik karena karyawan merasa nyaman dengan lingkungan fisik di dalam perusahaan maupun lingkungan non fisik yang ada di dalam perusahaan.

Hal tersebut menunjukkan bahwa lingkungan kerja bagian produksi PT. Bahagia Idkho Mandiri sudah baik sehingga berdampak pada kinerja karyawan yang dapat dilihat dari hasil adanya pengaruh antara lingkungan kerja terhadap kinerja karyawan. PT. Bahagia Idkho Mandiri melakukan berbagai macam cara untuk meningkatkan kualitas lingkungan kerja karyawan yaitu dengan memperbaiki suhu udara di ruang kerja, misalnya dengan menambahkan kipas angin atau AC di ruang kerja. Hal lain yang perlu juga dilakukan adalah memperbaiki sirkulasi udara yang ada di lokasi produksi. Hasil ini juga di kuatkan oleh peneliti sebelumnya yaitu Rumengan (2015) yang juga mendapatkan hasil yang signifikan.

\section{Pengaruh Beban Kerja Terhadap Kinerja Karyawan}

Berdasarkan hasil tabel 4.14 dapat disimpulkan bahwa variabel Beban Kerja berpengaruh positif signifikan terhadap kinerja karyawan. Hal ini ditunjukan dengan nilai original sample sebesar 0,405 dan nilai t-statistik sebesar 4,111 lebih besar dari t-tabel sebesar 1,96 dan hipotesis yang diterima, yang menyatakan bahwa apabila beban kerja diterima dengan baik maka hal itu menumbuhkan kinerja karyawan untuk tetap bekerja dengan baik di perusahaan.

Pada kenyataannya, aspek beban kerja dalam penelitian ini terbukti signifikan mempengaruhi kinerja karyawan PT. Bahagia Idkho Mandiri. Dengan demikian variabel beban kerja mempunyai pengaruh terhadap kinerja, jadi meningkatnya beban kerja akan diiringi oleh meningkatnya kinerja karyawan PT. Bahagia Idkho Mandiri karena kemampuan karyawan sudah sesuai dengan beban kerja yang diembannya.

Menurut Meshkati dalam Widyanti $d k k$,(2010) mendefinisikan beban kerja sebagai perbedaan antara kemampuan pekerja dengan tuntutan pekerjaan. Jika kemampuan pekerja lebih tinggi daripada tuntutan pekerjaan, akan muncul perasaan bosan.

Namun sebaliknya, jika kemampuan pekerja lebih rendah daripada tuntutan pekerjaan, maka akan muncul kelelahan yang lebih. Hasil ini juga dikuatkan oleh peneliti sebelumnya yaitu Adityawarman (2015) yang juga mendapatkan hasil yang signifikan.

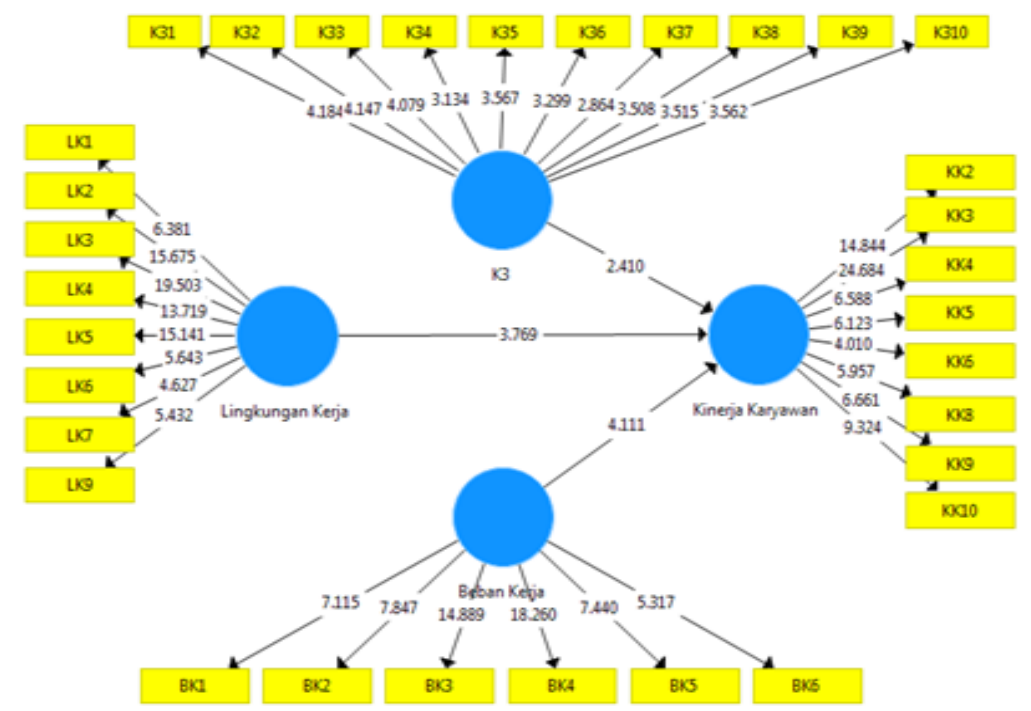

Gambar 3. Bootstrapping

Sumber: Output PLS 


\section{KESIMPULAN DAN SARAN \\ Kesimpulan}

Berdasarkan uraian-uraian dari pembahasan pada bab sebelumnya maka dapat peneliti simpulkPenelitian ini mencoba menganalisa variabel-variabel yang berkaitan dengan pengaruh Keselamatan Kesehatan Kerja (K3), Lingkungan Kerja dan Beban Kerja terhadap Kinerja Karyawan pada PT.Bahagia Idkho Mandiri. Dari hasil penelitian yang telah diperoleh dari perhitungan pengolahan data menggunakan PLS, maka dapat ditarik kesimpulan sebagai berikut:

1. Keselamatan Kesehatan Kerja (K3) berpengaruh positif dan signifikan terhadap kinerja karyawan pada PT. Bahagia Idkho Mandiri. Perusahaan memberikan pengaruh pada kinerja karyawan, dimana dengan menerapkan sistem K3 yang baik maka pekerja merasa aman serta terjaga kesehatannya sehingga mampu menampilkan kinerja yang prima dan produktivitas yang meningkat pada PT. Bahagia Idkho Mandiri.

2. Lingkungan Kerja secara persial berpengaruh positif signifikan terhadap Kinerja Karyawan pada PT. Bahagia Idkho Mandiri. Hal ini berarti semakin tinggi Lingkungan Kerja pada suatu perusahaan berdampak pada semakin tinggi kinerja pada perusahaan tersebut

3. Beban Kerja memiliki pengaruh signifikan terhadap Kinerja Karyawan pada PT. Bahagia Idkho Mandiri. Hal ini dikarenakan tugas yang diberikan perusahaan kepada karyawan terlalu berat maka karyawan merasa terbebani. Tingkat pembebanan yang terlalu tinggi memungkinkan pemakaian energi yang berlebihan dan terjadi overstress, sebaliknya intensitas pembebanan yang terlalu rendah memungkinkan rasa bosan dan kejenuhan atau understress.oleh karena itu perlu diupayakan tingkat intensitas pembebanan yang optimum yang ada diantara kedua batas yang ekstrim tadi dan tentunya berbeda antara individu yang satu dengan lainya.

\section{Saran.}

Berdasarkan hasil kesimpulan dalam penelitian ini, maka dapat diberikan saran-saran sebagai berikut:

\section{Saran untuk PT. Bahagia Idkho Mandiri}

Untuk meningkatkan kinerja yang baik tentunya perusahaan sebaiknya memperhatikan keselamatan kesehatan kerja, lingkungan kerja dan beban kerja yang diberikan kepada karyawannya karena dari hasil penelitian ini terbukti bahwa K3, lingkungan kerja dan beban kerja baik simultan maupun persial berpengaruh terhadap kinerja karyawan. Dan masih terjadi kecelakaan kerja yang disebabkan krena kelalaian pada karyawan, maka perusahaan perlu memberikan sanksi yang tegas kepada karyawan yang melanggar aturan-aturan mengenai keselamatan dan kesehatan kerja. Hal ini bertujuan agar karywan lebih disiplin dan juga untuk menghindari terjadinya kecelakaan akibat kerja. Berdasarkan penelitian ini perusahaan perlu meningkatkan standar keselamatan dan kesehatan kerja agar dapat memberikan rasa aman dalam bekerja sehingga meningkatkan kinerja kepada karyawan.

a. Selain K3, lingkungan kerja juga perlu di tingkatkan lagi fasilitas kerja yang ada di PT. Bahagia Idkho Mandiri masih terdapat yang kurang memadai sehingga perlu meningkatkan kualitas fasilitas kerja yang ada seperti menjaga kebersihan, meletakan barang-barang pada tempatnya yang rapih dan aman agar lingkungan kerja tetap bersih dan hubungan antar karyawan terjalin dengan baik, selain itu dapat menumbuhkan rasa kekeluargaan antar karyawan.

b. Pada variabel beban kerja nilai jawaban yang paling kecil adalah indikator ke tujuh, yaitu "Tugas yang diberikan sesuai dengan beban pekerjaan saya". Artinya sebagian besar responden merasa perusahaan memberikan tugas yang tidak sesuai dengan beban pekerjaan karyawan. Oleh karena itu, saran yang bisa dijadikan pertimbangan adalah perusahaan tidak memberikan tugas yang berlebihan kepada karyawan terlalu berat maka karyawan merasa terbebani. Tingkat pembebanan yang terlalu tinggi memungkinkan pemakaian energi yang berlebihan dan terjadi overstress, sebaliknya intensitas pembebanan yang terlalu rendah memungkinkan rasa bosan dan kejenuhan atau understress. Oleh karena itu perlu diupayakan 
tingkat intensitas pembebanan yang optimum yang ada diantara kedua batas yang ekstrim tadi dan tentunya berbeda antara individu yang satu dengan lainya.

\section{Saran untuk peneliti selanjutnya}

Saran untuk peneliti selanjutnya agar penelitian dapat dilakukan di perusahaan atau instansi lainnya, dengan mengembangkan kembali variable dan indikator yang belum digunakan dalam penelitian ini, seperti motivasi, ketrampilan kerja, sikap dan etika kerja sehingga diharapkan akan mendapatkan sebuah tujuan perusahaan yang baik

\section{DAFTAR PUSTAKA}

Adityawarman, Y. (2015). Pengaruh Beban Kerja Terhadap Kinerja Karyawan PT. Bank Rakyat Indonesia (persero) Tbk cabang krekot. Jurnal Manajemen dan Organisasi,, Vol. VI No. 1.

Ardana, K. M. (2012). Manajemen Sumber Daya Manusia, Cetakan Pertama, Yogyakarta: PT. Graha Ilmu.

Astianto, S. (2014). Pengaruh Stres Kerja dan Beban Kerja Terhadap Kinerja Karyawan PDAM SURABAYA. Jurnal Ilmu dan Riset Manajemen, Vol.3 No.7.

Bandar A, M. A. (2012). The Effect Of Human Resource Management Practices On Job Involvement In Selected Private Companies In Jordan. . Canadian Social Science, , 8 (2).50-57.

Carudin. (2011). pengaruh kepemimpinan Kepala Sekolah Dan Iklim Kerja Sekolah Terhadap Kinerja Guru. Jurnal Ekonomi dan Bisnis Indonesia, ISSN 1412-565X. Edisi Khusus No. 2, Agustus 2011.

Cudjoe, S. F. (2011). An Assessment Of Occupational Health And Safety Practices On Job Perfomance At The Hospital, Mmpong-Akuapem. Thesis. Program Pasca Sarjana, University of Science and Technology in Partial Fulfillment.

Ekaningsih. (2012). Pengaruh Motivasi Kerja Terhadap Kinerja dengan Persepsi Lingkungan Kerja sebagai Variabel Pemoderasi (Studi pada Satuan Polisi Pamong Praja Kota Surakarta). Jurnal Ilmu Sosial, Volume 4 No.1.

Ferdinand, A. (2014). Metode Penelitian Manajemen. Semarang:. Badan Penelitian Universitas Dipenogoro.

Ghozali, I. (2013). Aplikasi Analisis Multivariate Dengan Program SPSS, Edisi Tujuh. Semarang: BP Universitas Diponegoro.

Ghozali, i. (2014). Structural Equation Modeling. Metode Alternatif dengan Pertial Least Square $(P L S)$., Edisi 4 Semarang : Badan Penerbit Universitas Diponegoro.

Handoko, H. (2011). Dasar-Dasar Manajemen Produksi Dan Operasi Yogyakarta: BPFE.

Hariyati, M. (2011). Pengaruh Beban Kerja Terhadap Kelelahan Kerja Pada Pekerja Linting Manual Di PT. Djitoe Indonesia Tobacco Surakarta. Skripsi. Universitas Sebelas Maret Surakarta.

Hasibuan, M. (2012). Manajemen Sumber Daya Manusia. Edisi Revisi,Cetakan keenam belas. Jakarta: PT. Bumi Aksara.

Kemendagri. (Nomor 12 Tahun 2008). Peraturan Menteri dalam Negeri. Dipetik mei 10, 2013, dari www.depdagri.go.id: www.depdagri.go.id

Mangkunegara, A. A. (2010). Evaluasi Kerja SDM. Bandung: Refika Aditama.

Mas'ud, F. (2004). Survei Diagnosis Organisasional (Konsep dan Aplikasi) BP Universitas Dipenogoro, Semarang.

Mathis, R. \&., \& Jackson, J. (2006). Human Resource Management: Manajemen Sumber Daya Manusia. Terjemahan Angelia Dian.

Munandar. (2001). Psikologi Industry dan Organisasi. Universitas Indonesia, Jakarta.

Negara, K. M. (2004). tentang Pedoman Perhitungan Kebutuhan Pegawai Berdasarkan Beban Kerja dalam Rangka Penyusunan Formasi Pegawai Negeri Sipil., (hal. Nomor: KEP/75/M.PAN/7/2004).

Nitisemito, A. (2001). Manajemen Personalia. Penerbit Ghalia Indonesia: Jakarta. 
Novera, W. 2. (2010). Analisis Beban Kerja Dan Kebutuhan Karyawan Bagian Administrasi Akademik Dan Kemahasiswaan (Studi Kasus Unit Tata Usaha Departemen Pada Institut Pertanian Bogor). Skripsi.

Nurul, U. T. (2016). Manajemen Sumber Daya Manusia Bidang Pendidikan. Jakarta: Rajawali Press.

Prabu., M. A. (2010). Evaluasi Kerja Sumber Daya Manusia. Bandung: Refika Aditama.

Prashakti, R. D. (2019). MSDM mengelola sumber daya manusia di era revolusi industri 4.0 . yogyakarta: Wahana Resolusi, 2019.

Rivai, V. .. (2009). Manajemen Sumber Daya Manusia : Dari Teori ke Praktek (ed. 2). Jakarta : Rajawali Pers.

Rumengan, L. (2015). Analisis Lingkungan Kerja Terhadap Kinerja Pegawai Pada Fakultas Ekonomi dan Bisnis Unsrat Manado. Jurnal EMBA 2303-1774,, Vol.3, No.1.

Sedarmayanti. (2011). Tata Kerjadan Produktivitas Kerja. Bandung: CV Mandar Maju.

Sedermayanti. (2009). Tata Kerja Dan Produktivitas Kerja. Cetakan kedua. Bandung: Mandar Maju.

Shah, S. S. (2011). Workload and Performance of Employees. "Interdisciplinary Journal of Contemporary Research in Business Vol 3, No. 5 September 2011 (online)", (http://journalarchieves8.webs.com/256 Diakses 23 februari 2013).

Siagian, S. (2001). Manajemen Sumber Daya Manusia. Bumi Akasara Indonesia. Jakarta.

Siagian, S. P. (2010). Manajemen Sumber Daya Manusia, Cetakan Ke-13, Bumi Aksara, Jakarta.

Soleman, A. (2011). Analisis Beban Kerja Ditinjau Dari Faktor Usia Dengan Pendekatan Recommended Weiht Limit. ARIKA,. 5(2).

Sugiyono. (2010). Metodologi Penelitian Bisnis. Alfabeta, Bandung.

Sugiyono. (2011). Metode Penelitian Kuantitatif Kualitatif dan R\&D. Cetakan Ke-13. Penerbit Alfabeta. Bandung.

Sugiyono. (2012). Metode Penelitian Bisnis. Alfabeta, Bandung.

Sugiyono. (2014). Metode Penelitian Bisnis. Alfabeta, Bandung.

Suma'mur, P. (2009). Higene Perusahaan dan Kesehatan Kerja. Jakarta: Gunung Agung.

Sunyoto, D. (2012). Teori, Kuesioner, dan Analisis Data SUMBER DAYA MANUSIA. Yogyakarta: CAPS (Center for Academic Publishing Service). .

Suwatno., \&. J. (2011). Manajemen Sumber Daya Manusia. Bandung: Alfabeta.

Tarwaka. (2011). Beban Kerja (Workloud). Harapan Press, Solo.

Torang, S. (2012). Metode Riset Struktur \& Perilaku Organisasi.Alfabeta, Bandung.

Umar, H. (2005). Metode Riset Bisnis. PT. Gramedia Pustaka Umum. Jakarta.

Widyanti, A. (2010). Pengukuran Beban Kerja Mental dalam Seacrhing Task Dengan Metode Rating Scale Mental Ef fort (RSME). Jurnal Teknik Industri , V (1), 1-6. 19 Juni 2012.

Wirawan. (2009). Evaluasi Kinerja Manajemen Sumber Daya Manusia, Jakarta : Salemba Empat. Yani, H. (2012). Manajemen Sumber Daya Manusia. Jakarta: Mitra Wacana Media. 